\title{
A Study of Optimum Currency Area in East Asia: a Cluster Analysis
}

\author{
Saifuzzaman Ibrahim \\ University of York \\ University Putra Malaysia
}

\begin{abstract}
This paper studies the feasibility of ASEAN+3 Monetary Union by investigating the homogeneities of the countries. Utilizing techniques of cluster analysis on two sets of criteria, the Optimum Currency Area (OCA) and the adjusted Maastricht Treaty (MTC), reveals that homogeneities of ASEAN+3 are low and the immediate formation of a monetary union would entail serious potential costs. Furthermore, our findings suggest that grouping differ between pre-crisis and post-crisis periods which could be due to the different impact of the crisis on the economic structure of these countries.
\end{abstract}

- JEL Classification : F32, E52, F41

- Key Words: optimum currency area, cluster analysis, East Asia

\section{Introduction}

The 1997 Asian financial crisis has brought to the center the issue of appropriate exchange rate regimes especially for Asian countries affected by the crisis. In the decades prior to the 1997 crisis, many of the major Asian economies adopted a regime virtually pegged in nominal terms against the US dollar. This regime provided Asian countries with stable financial environment and encouraged foreign sources of capital for loans and investment. However, the 1997 crisis has seen

\footnotetext{
*Corresponding address: Saifuzzaman Ibrahim:University of York, Department of Economic and Related Studies, University of York, Heslington, York, YO10 5DD, United Kingdom, Tel : +44 (0)1904 424095, Fax : +44 (0)1904 433759, e-mail: si500@york.ac.uk 
many of the countries abandon this regime and switch to one with greater flexibility. Although the crisis has long subsided and the currencies are currently fairly stable, the issue of most appropriate exchange rate regime for Asia is as relevant as ever.

Countries that have integrated or are integrating their domestic capital market with the global capital market, like those of the emerging East Asia, are unable to sustain intermediate regimes and are forced to choose between a hard fix and a free floating regime, defining a corner solution (Obstfeld and Rogoff, 1995; Eichengreen, 1998). The intermediate regimes are hypothesized to be no longer tenable . However, according to Frankel (1999), the intermediate regimes are still useful and suitable for some economies that strive to gain from the optimal trade off between the advantages of stability and the advantages of flexibility. The intermediate regime is likely to continue as a viable option for emerging markets and is no more likely to disappear than the two corner solutions (Williamson, 2000).

The choice of an exchange rate arrangement varies with the particular circumstances of a country. The optimal regime changes over time due to the changes in a country's economic structure (Frankel, 1999). While the two-corner solutions is preferred among the industrialized countries, the intermediate regimes remain a popular choice for emerging markets (Bailliu and Murray, 2003). The selection between a fixed, float or intermediate regime would have to consider the advantages and disadvantages of the regime and the objectives of the country's policy. There is no single exchange rate regime that is most appropriate for all economies as countries have wide differences in the level of economic and financial development and in other aspects of their economies (Mussa et al., 2000).

Currency unions have been considered an alternative exchange rate regime in the literature. Economists predict that there will be more initiatives to form currency unions in the future, and this is largely triggered by three primary factors: the increasing number of countries in the world, globalization and the diminishing role of independent monetary policies especially for small countries (Barro, 2001). The recent international crises have eroded the credibility of unilateral fixed exchange rates and correspondingly increased interest in "harder" pegs, such as currency boards, adopting another country's money as the domestic currency and common currency arrangements (Bayoumi and Mauro, 1999). In the case of Asian countries, the debate on the adoption of a common currency is slowly emerging especially in the aftermath of the Asian crisis and the succession of the European 
Monetary Union (EMU) (Madhur, 2002). This has intensified by the recent proposal to form the Asian Monetary Union (AMU) by the Asian Development Bank (ADB). Currently, ADB is working toward creating the Asian Currency Unit (ACU), an index of currencies which is quite similar, both in terms of objectives and structure, to the European Currency Unit. The ACU is regarded as the first step toward an integrated Asian currency and a more coordinated economic cooperation. It is formed to facilitate economic interdependence in Asia, cooperation on exchange rate stability and the introduction of a single currency.

The purpose of this study is to examine the feasibility of the AMU, which is represented by ASEAN+3, by examining the homogeneity of the economies. ASEAN +3 consist of ten countries from ASEAN (Association of the Southeast Asian Nations) which are Brunei, Cambodia, Indonesia, Laos, Malaysia, Myanmar, the Philippines, Singapore, Thailand and Vietnam, and three other East Asian countries, China, Japan and Korea. However for this study ASEAN+3 is defined as a group of five ASEAN core members (Indonesia, Malaysia, the Philippines, Singapore and Thailand) plus China, Japan and Korea.

Many studies have investigated the viability of Asian Optimum Currency Area (OCA), for example, Bayoumi and Eichengreen (1994), Wyplosz (2001), Lee, Park and Shin (2002), McKinnon and Schnabl (2003), and Tsang (2002). These studies have produced mixed results; some find that Asia is a viable OCA while others produce negative findings. This study offers a new approach to this issue by investigating the viability of Asian OCA through the homogeneity of the regional economies based on the criteria outlined by the OCA theory and the Maastricht Treaty. We adopt a cluster analysis technique that, to the best of our knowledge, has not been used in the previous studies of Asian OCA. We also use samples of countries which are different from those used in the existing literature on this issue. The selection of five core ASEAN countries and the three Far East Asian economies is based on the fact that they are believed to be the most active Asian countries in the activities of economic integration in the region.

Using cluster analysis, this study groups the countries into respective categories based on the criteria outlined by the Optimum Currency Area (OCA) theory and the adjusted Maastricht Treaty criteria. The results suggest that AMU among the ASEAN+3 is not an optimal monetary union due to the non-homogeneity of the economies, which would make it very difficult for the group to adopt a 'one size fits all' policy. The rest of this paper is organized as follows. The following section details the background of the OCA and the Asian OCA. Section III presents the 
cluster analysis, technique used in this study. Section IV describes the selection of data. Sections V and VI present the results of the analysis and the discussion of the results respectively. Section VII concludes the study.

\section{Background}

\section{A. Optimum Currency Area}

An OCA (Mundell, 1961), is defined as a group of countries that is optimal to have a common currency and monetary policy. OCA defined optimality as a situation that occurs when the usefulness of the nominal exchange rate as an adjustment tool is reduced by fostering internal and external balances, reducing the impact of some types of shocks, or facilitating adjustment thereafter (Mongelli, 2005). Countries which have positively correlated shocks among them are more suitable to form a currency union because they can use union-wide policies in combating the imbalances (Mundell, 1961). A currency union is also more suitable for economies with large tradable sectors because the loss of the nominal exchange rate as an instrument of monetary policy would not be of much concern as it is less effective compared to domestic policy (McKinnon, 1963). Additionally, economies that have large volumes of mutual trade are also more conducive to form a currency union as it can minimize the loss in currency exchange through the reduction or elimination of transaction cost and exchange rate uncertainty. However, the OCA countries should maintain inflation rate similarities to avoid external imbalances (Fleming, 1976). The similarity of inflation rates between countries will ensure the stability of terms of trade and encourage current account transactions and trade to be in equilibrium. Thus, it reduces the need for nominal exchange rate adjustments.

The most prominent example of currency union is the European Monetary Union (EMU), which is launched in January 1999. Prior to the formation, all 11 countries signed the Maastricht Treaty in 1992, which underlined the criteria to qualify for membership of the EMU. The criteria require convergence in some nominal economic factors including inflation rate, nominal interest rates, nominal exchange rates, government deficits and government debt.

\section{B. Asian OCA}

The successful launch of the EMU has sparked new interest in a potential Asian 
currency union. Bayoumi and Eichengreen (1994) proposed that Asia can be grouped into two OCAs, namely the Northern Asia, bloc of Japan, Korea and Taiwan, and the Southeast Asian, bloc of Hong Kong, Indonesia, Malaysia, Singapore and Thailand. They also suggested that these two Asian blocs are even better qualified than the Northern European bloc of Austria, Belgium, Denmark, France, Germany, the Netherlands and Switzerland. Wyplosz (2001) also found the feasibility of East Asia as an OCA despite lacking a developed framework of trade agreement and other financial and government institutions compared to EMU. Despite some encouraging results of OCA studies on Asia (Saxena, 2003 and Trisvisvavet, 2001), the debate remains that Asia is still not ready for an OCA. For example, Lee, Park and Shin (2002), McKinnon and Schnabl (2003), and Tsang (2002) do not find favourable results on the Asian Monetary Union. The different stages of economic development, the lack of effective institutional arrangements, and the diverse political structures are among the barriers to form a currency union among the Asian countries. Examining the degree of openness, the degree of product diversification, the industrial structure, inflation rates and the degree of correlation of macroeconomic variable, Sterner and Skoog (2003) discovered that the ten ASEAN countries do not constitute a viable OCA.

\section{Cluster Analysis}

This paper employs cluster analysis to test the similarities and dissimilarities of the economic structures of the ASEAN+3 countries. Cluster analysis is a wellknown technique to group similar objects of people, things, and events into respective categories and encompasses a number of different algorithms and methods. For this study, a set of economic variables are used to proxy the adjusted Maastricht Treaty and the OCA criteria. Specifically, the study utilizes two approaches of cluster analysis, a partitioning-type fuzzy cluster analysis and an agglomerative nesting hierachical clustering analysis.

\section{A. Fuzzy Cluster Analysis}

Fuzzy cluster analysis, a partitioning method of clustering algorithms, is often better suited for data with unclear or undefined boundary between the clusters. Fuzzy clustering shows the degree to which an item belongs to a cluster and the algorithm computes membership coefficients, quantified by the degree of belongingness in the range of 0 to 1 . Fuzzy clustering proves to be better than hard 
clustering because it yields more detailed information on the structure of the data.

The analysis in this study is based on Kaufman and Rousseuw (1990). The dataset consists of $n$ countries and for each country there are $p$ variables (using the Maastricht Treaty or the OCA criteria), which are denoted by $x_{n p}=\left\{x_{1}, x_{2}, \ldots, x_{n}\right\}$ where each $x_{i}=\left\{x_{i l}, \ldots, x_{i p}\right\}$. Each variable is standardized with mean zero and standard deviation of one. This is to prevent a variable with high variance from dominating the cluster analysis and to allow all criteria to be equally valued.

The dissimilarity coefficient or distance, $d(i, j)$ between two countries $X_{i}$ and $X_{j}$ is defined as the Euclidean distance:

$$
d(i, j)=\sqrt{\sum_{k=1}^{p}\left(x_{k i}-x_{k j}\right)^{2}}
$$

The objective of the algorithm of fuzzy clustering analysis is to minimize the function:

$$
C=\sum_{v=1}^{k} \frac{\sum_{i, j=1}^{n} u_{i v}^{2} u_{j v}^{2} d(i, j)}{2 \sum_{j=1}^{n} u_{j v}^{2}}
$$

subject to: $u_{i v}$ for $i=1, \ldots, \mathrm{n} ; v=1, \ldots, n$

$$
\sum_{v} u_{i v}=0 \text { for } i=1, \ldots, n
$$

in which $u_{i v}$ represents the unknown coefficient of membership of country $i$ to cluster $v$, and $k$ represents the number of cluster into which the data are partitioned. The matrix of coefficients $U_{n x k}$ is produced by the algorithm with rows of the matrix summing to one and showing the degree of belongingness of that country to each of the group. If one of the coefficients is very high then it can be said that there is a high degree of certainty that this country belongs to that group. Otherwise, this country is not easily classified.

Several statistics are used to analyze how the data are partitioned. One is the normalized Dunn coefficient, which is defined as the sum of squares of all the membership coefficients, divided by the number of countries:

$$
F_{k}=\frac{\frac{k}{n} \sum_{i=1 v=1}^{n} \sum_{i v}^{k} u_{i v}^{2}-1}{k-1}
$$


The Dunn coefficients vary between 1 indicating well-partitioned data to 0 indicating complete fuzziness of the data. The value reaches 1 only if, for each country, there are one coefficient equal to 1 and the other to 0 , and 0 when all the coefficients of belongingness are $1 / k$.

Another useful statistic is the silhouette width, which is defined as:

$$
S(i)=\frac{b(i)-a(i)}{\max (a(i), b(i))}
$$

where $a(i)$ is the average dissimilarity of country $i$ to all countries in the same cluster and $b(i)$ is the minimum average dissimilarity across all other clusters, of country $i$ to all countries in each cluster. If the value of $s(i)$ is close to 1 , the country is said to be well classified but if the value is close to 0 , there is ambiguity in deciding which cluster the country might belong to. A negative silhouette width indicates that the country is misclassified. The corresponding average for each cluster and for the total dataset indicate how well the data in each cluster and the total data set were partitioned.

\section{B. Agglomerative Method - Group Average Linkage Method}

There are several types of agglomerative methods and they differ in the way the similarity (or distance) between clusters is defined. This study adopts the Group Average Linkage Method. Similar to the fuzzy clustering method, the dataset of the study are assumed to consist of $n$ countries and for each country, there are $p$ variables (using the Maastricht Treaty or the OCA criteria), which are denoted by $X n p=\{x 1, x 2, \ldots, x n\}$ where each $x i=\{x i 1, \ldots, x i p\}$.

The distance, $d(i, j)$ between two countries $X_{i}$ and $X_{j}$ is defined as the Euclidean distance, similar to the one in the previous sub-section. Meanwhile, the dissimilarity between two clusters, and, is defined by the dissimilarity coefficient which is measured as:

$$
d\left(\omega_{j}, \omega_{k}\right)=\frac{1}{\left|\omega_{j}\right|\left|\omega_{k}\right|} \sum_{\substack{j \in \omega_{j} \\ k \in \omega_{k}}} d(j, k)
$$

where $\left|\omega_{i}\right|$ and $\left|\omega_{j}\right|$ denote the number of countries in the cluster, $\omega_{j}$ and $\omega_{k}$, respectively. The group average linkage method starts from a classification denoted by $\Omega_{0}=\left[\omega_{1}^{0}, \ldots, \omega_{N}^{o}\right]$ with $\mathrm{N}$ clusters, where each cluster contains only one country. The process continues by successively merging two clusters into one at each stage until a single cluster is obtained. The criterion used in deciding which 
pair of cluster should be merged is based on which two have the least dissimilarity, and the dissimilarity between clusters may be updated once a new cluster is produced. The process of merging will produce a mathematical and graphic representation of the clustering procedure which is called a dendogram (tree diagram).

\section{Data}

In this study, ASEAN+3 would be represented by five core-ASEAN members which are Indonesia, Malaysia, Philippines, Singapore and Thailand; and the plus three countries of China, Japan and South Korea. In what follows, ASEAN+3 is referred as a group of countries described above. Data for this study are split into two periods, the pre-crisis period running from 1991 to 1997 and the post-crisis period running from 1998 to 2004. This enables us to examine the impact of the 1997 Asian crisis on the economic structure of the countries. As cluster analysis measures the similarities between data, this study nominates Japan as the centre country and the chosen variables are measured relative to Japan.

\section{A. Clustering Based on the Adjusted Maastricht Treaty Criteria}

The first set of data are adjusted from criteria outlined by the Maastricht Treaty for nominal convergence. The original criteria suggest that a country must have an inflation rate within $1.5 \%$ of the average inflation rate of the three members with the lowest inflation rates, a long-run bond yield within $2 \%$ of the average bond yields of the same three countries, an exchange rate within $\pm 15 \%$ ERM bounds for at least two years, budget deficit of no higher than 3\% of the GDP and public debt that is less than $60 \%$ of the GDP. However, this study adjusts some of the criteria to suit ASEAN+3 which comprises mainly by emerging economies.

Terminology that is used in this study is hereby defined. Budget deficit as percentage of GDP, which is the average of the country's budget deficits as percentage of GDP in the relevant period, represents the performance of the country's budget deficit. Debt as percentage of GDP, which is the average national net external debt as percentage of GDP in the relevant period, represents the performance of the country's debt. Although the Maastricht treaty criteria focus on domestic debt, this study uses external debt because this is more important and crucial for emerging economies like ASEAN+3. Volatility of exchange rate is represented by the standard deviation of the log difference of the nominal exchange 
rate. Similarity of inflation among the countries is represented by inflation differential, which is measured by the average difference between the annual inflation rate in each country and the annual inflation in Japan for the relevant period. Interest rate is measured by the average of annual prime lending rate of each country for the relevant period.

Bayoumi and Eichengreen (1997b) asserted that the criteria laid out by the Maastricht Treaty do not ensure the real convergence, which is crucial for a monetary union to function. This is why we also adopt criteria that based on OCA theory.

\section{B. The Clustering Based on OCA Criteria}

The second set of data are based on the OCA theory (Mundell, 1961; McKinnon, 1963; De Grauwe, 1994). In this study, the selection of variables in analyzing the economic convergence of ASEAN+3 was inspired by the OCA criteria following the work by Artis and Zhang (2001) and Boreiko (2003). The variables used in this study are as follows:

(1) Volatility in Real GDP

In this study, the standard deviation of the difference of the logarithm of real GDP (as a proxy for output) between the candidate ( $i$ ) and the respective reference country $(j)$ is taken to represent the synchronization in business cycle.

\section{(2) Volatility in Real Exchange Rate}

It is argued that exchange rate could be used as an instrument to counteract an unfavorable shock. However, the benefits from a separate exchange rate would be minimal if there is little cause for variation in the real exchange rate, hence, the cost of moving to a single currency can be assumed to be small. In this study, the standard deviation of the log difference of the real exchange rate is taken to represent the real exchange rate variability, where deflation is accomplished using the relative consumer price index.

\section{(3) Volatility in Interest Rates}

This variable may be interpreted as an indicator of coordination in monetary policy of a country with that of the reference country, Japan. In the OCA theory, one important criterion for a successful monetary union is the willingness to commit to partner country's policies with greater counter-inflationary credibility. The volatility of interest rate against the Japanese interest rate is calculated as the standard deviation of the difference in the logarithm of real interest rate between the candidate $(i)$ and the respective reference country $(j)$. 


\section{(4) Openness to Trade}

The OCA theory entails that larger trade volumes between countries in the OCA lead to greater benefits of a common currency because it results in greater savings in transactions costs. The bilateral trade intensity for any country $i$ is measured as $\left(x_{i j}+m_{i j}\right) /\left(x_{i}+m_{i}\right)$, where $x_{i}$ and $m_{i}$ are exports and imports (of goods) for country $i$ and subscript $j$ indicates the destination or source Japan, the reference country in this study.

\section{(5) Convergence of Inflation}

It has often been noted that the traditional OCA theory was built during the 'fixprice' era, thus, it offers principally real variables as criteria. Therefore, introducing inflation convergence as a criterion could be regarded as an appropriate normalization (Artis and Zhang, 2001). The criterion would be measured by the difference between the inflation rate of the candidate $\left(x_{i}\right)$ and that of the reference country $\left(x_{j}\right)$.

\section{Results}

\section{A. Individual OCA and the Adjusted Maastricht Treaty Criteria}

We start our discussion by reviewing some features of Maastricht Treaty criteria (MTC) and OCA data in period 1991-1997 and period 1998-2004 which are summarized in Table 1 and Table 2, respectively.

Table 1 shows that during the period 1991-1997, most countries registered budget surpluses except the Philippines and China. Singapore recorded the highest budget surplus at around 6.7 percent of GDP. On the net foreign debt, Singapore occupies the lower group with China and Korea, while three countries, Indonesia, the Philippines and Thailand, experienced net foreign debt of more than 50 percent of their GDP. In terms of exchange rate volatility, the countries are quite similar to each other except for China whose volatility is twice as much as that of the average. Indonesia, the Philippines and China are the three countries with the highest inflation differential of above 7 percent, while Singapore is alone in the lower group at 1.1 percent. Singapore again has the lowest average interest rate at 6.2 percent, while Indonesia and the Philippines are in the higher group of above 16 percent.

The period 1998-2004 presents a different story. Most countries recorded budget deficits with Malaysia and the Philippines being the highest two. Only Singapore 
Table 1. The Adjusted Maastricht Treaty Criteria

\begin{tabular}{ccccccccccc}
\hline & \multicolumn{2}{c}{ Deficit } & \multicolumn{2}{c}{ Debt } & \multicolumn{2}{c}{ Volatility of ER } & \multicolumn{2}{c}{ Inflation Differential } \\
\hline \multirow{2}{*}{ Indonesia } & $1991-1997$ & $1998-2004$ & $1991-1997$ & $1998-2004$ & $1991-1997$ & $1998-2004$ & $1991-1997$ & $1998-2004$ & $1991-1997$ & $1998-2004$ \\
\cline { 2 - 9 } Malaysia & 0.543 & -1.571 & 54.843 & 83.629 & 4.109 & 19.282 & 7.153 & 17.296 & 21.114 & 20.971 \\
Philippines & -0.229 & -3.986 & 61.614 & 79.671 & 4.513 & 3.918 & 7.633 & 5.809 & 16.870 & 11.507 \\
Singapore & 6.743 & 0.400 & 10.371 & 19.886 & 3.933 & 3.237 & 1.069 & 0.879 & 6.250 & 5.816 \\
Thailand & 1.929 & -1.614 & 51.100 & 58.586 & 3.994 & 3.721 & 3.827 & 2.719 & 12.849 & 8.114 \\
China & -1.271 & -3.100 & 15.943 & 14.157 & 9.968 & 4.099 & 9.719 & 0.730 & 10.003 & 5.734 \\
Korea & 0.700 & 0.143 & 19.871 & 26.986 & 3.948 & 5.294 & 4.533 & 3.829 & 9.543 & 8.543 \\
\hline
\end{tabular}

Table 2. The OCA Criteria

\begin{tabular}{ccccccccccc}
\hline & \multicolumn{2}{c}{ Volatility of Real GDP } & \multicolumn{2}{c}{ Volatility of Real ER } & \multicolumn{2}{c}{ Vol. of Real Int Rates } & \multicolumn{2}{c}{ Trade } & \multicolumn{2}{c}{ Inflation Differential } \\
\hline \multirow{2}{*}{ Indonesia } & $1991-1997$ & $1998-2004$ & $1991-1997$ & $1998-2004$ & $1991-1997$ & $1998-2004$ & $1991-1997$ & $1998-2004$ & $1991-1997$ & $1998-2004$ \\
\cline { 2 - 10 } Malaysia & 3.873 & 3.494 & 4.210 & 14.336 & 14.940 & 8.684 & 25.841 & 19.337 & 7.153 & 17.296 \\
Philippines & 4.085 & 4.501 & 4.411 & 4.795 & 18.919 & 6.457 & 19.510 & 14.785 & 2.470 & 2.506 \\
Singapore & 7.668 & 2.026 & 3.907 & 3.355 & 17.096 & 2.382 & 14.574 & 10.613 & 1.069 & 0.879 \\
Thailand & 2.317 & 2.830 & 4.410 & 3.109 & 18.265 & 9.888 & 18.906 & 18.796 & 3.827 & 2.719 \\
China & 8.129 & 6.055 & 7.738 & 4.040 & 20.446 & 2.235 & 18.622 & 16.804 & 9.719 & 0.730 \\
Korea & 3.497 & 5.201 & 4.088 & 4.738 & 19.142 & 10.058 & 15.194 & 14.348 & 4.533 & 3.829 \\
\hline
\end{tabular}


and Korea experienced budget surplus though the figure for Singapore reduced substantially to only 0.4 percent of the GDP. In terms of net foreign debt as percentage of GDP, all countries recorded higher value compared to those in the previous period. Two countries, Indonesia and the Philippines are in the higher group with figures reaching 80 percent. Singapore, although recorded an increase in its net foreign debt, still belonged in the lower group together with China and Korea. In terms of the volatility of exchange rate, Indonesia is the only country that registered a significant substantial increase compared to the value in the pre-crisis period while other countries do not record significant changes. For inflation differential and interest rate, Indonesia once again belonged to the higher group with a huge difference with those of the rest of the other countries. Singapore and China, on the other hand, are in the lower group for both categories.

With respect to the OCA data from 1991-1997, Singapore and China are in the higher group in terms of the volatility of the real GDP. For other countries, their real GDP volatilities are almost similar except Thailand which has the lowest at 2.3. The countries also show approximately similar volatility of real exchange rate, except China whose exchange rate volatility is significantly higher than those of the others. In terms of the volatility in real interest rates, China is once again in the higher group while Indonesia and the Philippines occupy the lower group. For trade with Japan, Indonesia is the highest at 25.8 percent while Malaysia, the Philippines, Thailand and China are in the middle group with the range between 18 to 20 percent, and Singapore and Korea are in the lower group. Indonesia, the Philippines and China are at the high end of inflation gap ranging between 7 to 10 percent, while Singapore's average inflation gap is just 1.1 percent.

In the post crisis of 1998-2004, China continues to be in the higher group for the volatility in real GDP together with Korea. Singapore, which belonged to the higher group before the crisis, has moved to the lower group together with Thailand. All countries show similar volatility in terms of real exchange rate against Japan except Indonesia whose real exchange rate was three to four times more volatile than those of the rest. Indonesia remains in the higher group for the volatility of real interest rates together with Thailand and Korea. The interest rates of Singapore and China are the least volatile among the countries. In terms of the percentage trade with Japan, though Indonesia registered a lower value compared to the pre-crisis period, the country is still in the higher group together with the Philippines and Thailand, while Singapore continues to be in the lower group. On inflation differential, Indonesia's inflation is substantially higher than that of other 
countries while Singapore and China are the two countries in the lower group.

Based on the above discussion on the patterns of data of the ASEAN +3 countries according to both the OCA and the adjusted Maastricht Treaty, it is evident that the economies are non-homogeneous. We extend this analysis by clustering the countries according to the MTC or OCA criteria utilizing two types of cluster analysis, fuzzy and group average.

\section{B. Ensitivity Analysis of Different Cluster Techniques}

Table 3 presents the results of clustering using data according to the adjusted Maastricht Treaty and utilizing both the fuzzy cluster and the group average cluster method.

Both clustering methods produces identical results during the pre-crisis period. The results, however, differ after the Asian financial crisis. China is grouped in Group 2 with Malaysia, the Philippines and Thailand using the fuzzy cluster analysis after the crisis but, is placed in Group 3 with Singapore and Korea using the group average cluster analysis. Interestingly, looking more closely at the coefficient statistics of both methods (Table A2 in Appendix), China does not really belong to either group. Referring to Table A2, China's belongingness coefficients using the fuzzy cluster method in Group 2 and 3 are 0.46 and 0.43 , respectively which reveals that China is located between these two groups. However, using the group average cluster method, China is merged with the Singapore and Korea only when the dissimilarity coefficient is at 1.88 at stage 5, while the Singapore and Korea group is formed at stage 1 when the dissimilarity coefficient is at 0.86 (Refer to Table 6). This shows that the similarity between

Table 3. ASEAN +3 Classification based on MTC Data

\begin{tabular}{|c|c|}
\hline Fuzzy Cluster Analysis & Group Average Cluster Analysis \\
\hline \multicolumn{2}{|c|}{ 1991-1997 } \\
\hline 1. Indonesia, Philippines & 1. Indonesia, Philippines \\
\hline 2. Malaysia, Thailand. Korea & 2. Malaysia, Thailand. Korea \\
\hline 3. Singapore & 3. Singapore \\
\hline 4. China & 4. China \\
\hline \multicolumn{2}{|c|}{$1998-2004$} \\
\hline 1. Indonesia & 1. Indonesia \\
\hline 2. Malaysia, Philippines, Thailand, China & 2. Malaysia, Philippines, Thailand \\
\hline 3. Singapore, Korea & 3. Singapore, China, Korea \\
\hline
\end{tabular}


Table 4. ASEAN +3 Classification on OCA Data

\begin{tabular}{ll}
\hline \multicolumn{1}{c}{ Fuzzy Cluster Analysis } & \multicolumn{1}{c}{ Group Average Cluster Analysis } \\
\hline \multicolumn{1}{c}{$1991-1997$} \\
\hline 1. Indonesia, Philippines & 1. Malaysia, Thailand, Korea \\
2. Malaysia, Singapore, Thailand, Korea & 2. Indonesia, Philippines \\
3. China & 3. Singapore \\
& 4. China \\
\hline \multicolumn{2}{c}{$1998-2004$} \\
\hline 1. Malaysia, Philippines, Thailand, Korea, & 1. Malaysia, Philippines, Thailand, \\
China & Korea \\
2. Singapore & 2. China \\
3. Indonesia & 3. Singapore \\
& 4. Indonesia \\
\hline
\end{tabular}

China and the other two countries is relatively low.

Results of clustering the ASEAN +3 countries according to the OCA criteria using both analysis methods are summarized in Table 4. For the period 1991-1997, both methods produce similar groups except for the case of Singapore, which is put in Group 2 together with Malaysia, Thailand and Korea using the fuzzy cluster analysis but is alone in Group 3 using group average cluster method. Although Singapore is placed in Group 2 in the fuzzy cluster method, its belonginess coefficient (0.54) is the lowest in the group indicating that the country has the lowest similarity in the group. For the post crisis period, both types of cluster methods produce very similar results except for the case of China. China is placed in Group 1 together with Malaysia, Thailand and Korea using the fuzzy cluster method but remains on its own in Group 2 using the group average cluster method. Overall, the grouping of the ASEAN + 3 countries based on the adjusted Maastricht Treaty and the OCA theory using both fuzzy and group average cluster methods produces very similar groupings, which suggests that the results are not over-sensitive to the types of cluster analysis employed. Thus, for convenience, we turn our discussion on the results using group average clustering method in the following section.

\section{Results of Group Average Cluster Analysis}

\section{(1) Grouping by MTC Data}

The summaries of the merging process are presented in Table 5 and Table 6 while the illustrations are presented in Figure 1 and Figure 2. For 1991-1997 
Table 5. Group Average Clustering Agglomeration Schedule (1991-1997: MTC)

\begin{tabular}{|c|c|c|c|c|}
\hline \multirow{2}{*}{ Stage } & \multicolumn{2}{|c|}{ Cluster Combined } & \multirow{2}{*}{$\begin{array}{l}\text { Dissimilarity } \\
\text { Coefficients }\end{array}$} & \multirow{2}{*}{$\begin{array}{c}\text { Number of } \\
\text { Clusters }\end{array}$} \\
\hline & Cluster X & Cluster Y & & \\
\hline 1 & Indonesia & Philippines & 0.9739 & 6 \\
\hline 2 & Malaysia & Thailand & 1.1136 & 5 \\
\hline 3 & Cluster 2 & Korea & 1.4419 & 4 \\
\hline 4 & Cluster 1 & Cluster 3 & 2.4612 & 3 \\
\hline 5 & Cluster 4 & Singapore & 3.6426 & 2 \\
\hline 6 & Cluster 5 & China & 3.9534 & 1 \\
\hline
\end{tabular}

samples, the optimal number of groups is four. The first group is comprised of two countries, Indonesia and the Philippines, the second group contains three countries, namely Malaysia, Thailand and Korea, while Singapore and China are both alone in the third and fourth groups (Refer to Table 4).

The first group, Indonesia and the Philippines, merged together at stage 1 with the dissimilarity coefficient of 0.97 indicating that these two countries have the most similar economic structures based on MTC. This first group merged with other countries only at stage 4 which indicate that these two countries do not share certain features with other countries, which are high percentage of net foreign debt to GDP, high inflation differential and high interest rates. The second group consists of Malaysia, Thailand and Korea, put together primarily due to the average exchange rate volatility, average inflation differential and average level of interest

Figure 1. Dendogram of Group Average Clustering (Maastricht Treaty 1991-1997)

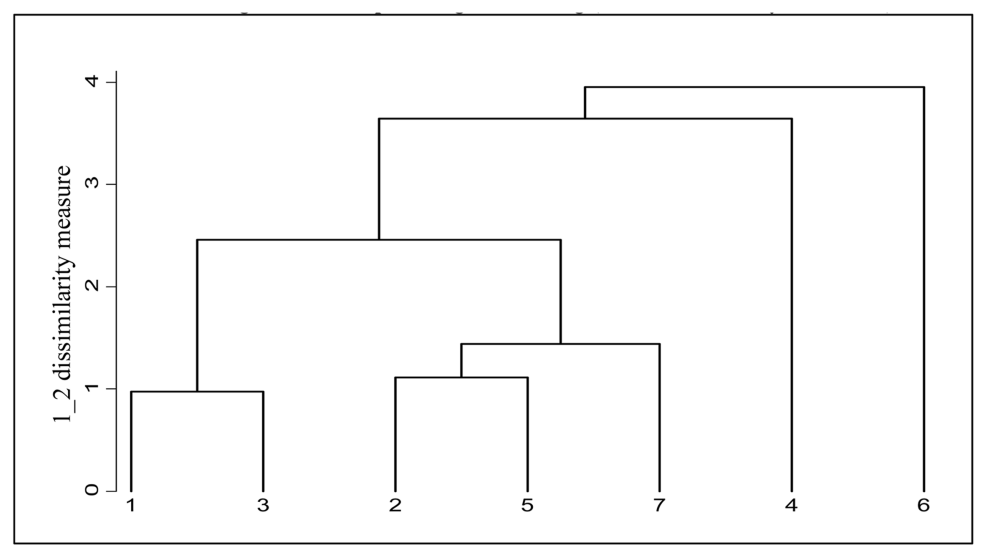

*Note: 1=Indonesia, 2=Malaysia, 3=Philippines, 4=Singapore, 5=Thailand, 6=China, 7=Korea 
Figure 2. Dendogram of Group Average Clustering (Maastricht Treaty 1998-2004)

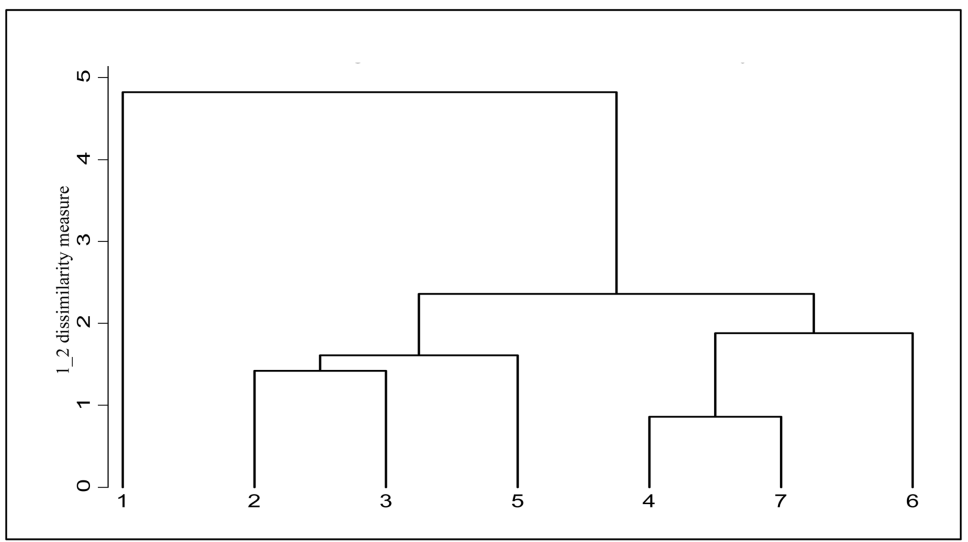

*Note: 1=Indonesia, 2=Malaysia, 3=Philippines, 4=Singapore, 5=Thailand, 6=China, 7=Korea

rates. However, Malaysia is more similar to Thailand as they came together at the dissimilarity coefficients of 1.11 at stage 2 before they are joined by Korea at the coefficient of 1.44 at stage 3 . The third group comprises of Singapore alone. The country only merged with others at stage 5 when the dissimilarity coefficient is at 3.64. Singapore has its distinct features that include low budget deficits, low inflation differentials and low interest rates. The fourth group also has only one country, China. The country does not join any group until the final stage. This indicates that China has the least similar economic structure and has distinct feature of high volatility in the exchange rate.

During the period 1998-2004, group average cluster method produces several noticeable changes in grouping as shown in Table 6 and Figure 2. The first group contained Malaysia, the Philippines and Thailand. The merging process for the first

Table 6. Group Average Clustering Agglomeration Schedule (1998-2004: MTC)

\begin{tabular}{|c|c|c|c|c|}
\hline \multirow{2}{*}{ Stage } & \multicolumn{2}{|c|}{ Cluster Combined } & \multirow{2}{*}{$\begin{array}{l}\text { Dissimilarity } \\
\text { Coefficients }\end{array}$} & \multirow{2}{*}{$\begin{array}{c}\text { Number of } \\
\text { Clusters }\end{array}$} \\
\hline & Cluster X & Cluster Y & & \\
\hline 1 & Singapore & Korea & 0.8580 & 6 \\
\hline 2 & Malaysia & Philippines & 1.4211 & 5 \\
\hline 3 & Cluster 2 & Thailand & 1.6088 & 4 \\
\hline 4 & Cluster 1 & China & 1.8825 & 3 \\
\hline 5 & Cluster 3 & Cluster 4 & 2.3564 & 2 \\
\hline 6 & Indonesia & Cluster 5 & 4.8210 & 1 \\
\hline
\end{tabular}


group has Malaysia merging with the Philippines with the dissimilarity coefficient of 1.42 at stage 2 and Thailand joined them at coefficient of 1.61 at stage 3 . The group only merged with another group at stage 5 with the coefficient of 2.36 and their common features are average exchange rate volatility and inflation differential.

The second group consists of Singapore, Korea and China. Singapore merged with Korea at stage 1 with the dissimilarity coefficient of 0.86 and China joined them 1.88 coefficient at stage 4 . The merging process suggests that the economies of Singapore and Korea have the highest similarity among the ASEAN+3. It may be of interest to note that China is grouped with Singapore and Korea when the group average method is used, but merged with Malaysia, the Philippines and Thailand when the fuzzy method is used. The dissimilarity coefficients and the belonginess coefficient of China suggest that the country may be in its own group that link the group of Singapore and Korea and the group of Malaysia, Philippines and Thailand. If China is taken out of the group, Singapore and Korea both share several common characteristics, namely low budget deficits, low percentage of debt and average exchange rate volatility. However, with China in the group, all three groups share only one common feature, which is low external debt level. The algorithms put Indonesia alone in the fourth group and the country only merged with other countries at the final stage. This indicates that on the basis of the MTC criteria, the Indonesian economy is quite different from other countries. This may be due to its exclusive features of high exchange rate volatility, high inflation differential and high interest rates.

\section{(2) Grouping by OCA Criteria}

Clustering ASEAN +3 countries in the pre-crisis period based on the OCA

Table 7. Group Average Clustering Agglomeration Schedule (1991-1997: OCA)

\begin{tabular}{|c|c|c|c|c|}
\hline \multirow{2}{*}{ Stage } & \multicolumn{2}{|c|}{ Cluster Combined } & \multirow{2}{*}{$\begin{array}{l}\text { Dissimilarity } \\
\text { Coefficients }\end{array}$} & \multirow{2}{*}{$\begin{array}{c}\text { Number of Clus- } \\
\text { ters }\end{array}$} \\
\hline & Cluster X & Cluster Y & & \\
\hline 1 & Thailand & Korea & 1.2365 & 6 \\
\hline 2 & Malaysia & Cluster 1 & 1.4975 & 5 \\
\hline 3 & Indonesia & Philippines & 1.8737 & 4 \\
\hline 4 & Cluster 2 & Singapore & 2.4232 & 3 \\
\hline 5 & Cluster 3 & Cluster 4 & 3.0898 & 2 \\
\hline 6 & Cluster 5 & China & 4.1568 & 1 \\
\hline
\end{tabular}


Figure 3. Dendogram of Group Average Clustering (OCA 1991-1997)

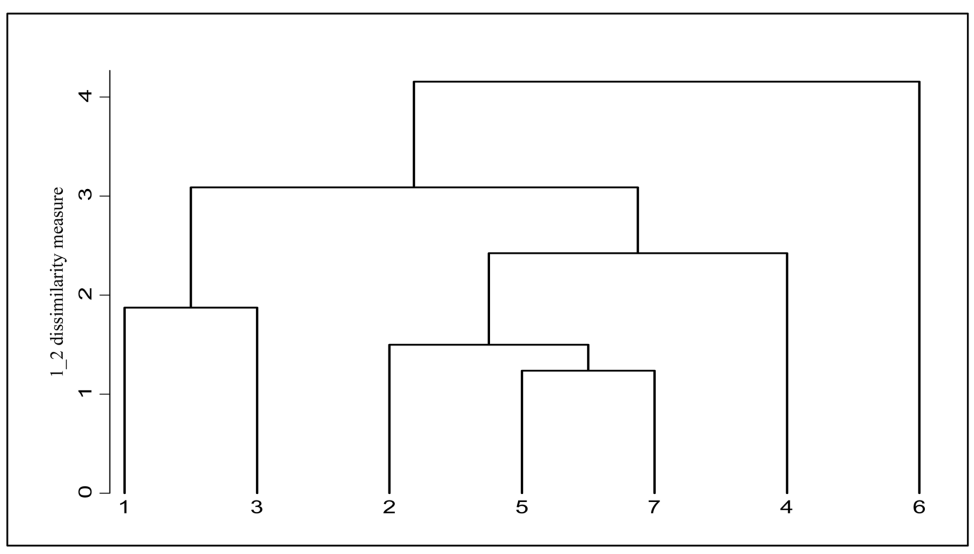

*Note: 1=Indonesia, 2=Malaysia, 3=Philippines, 4=Singapore, 5=Thailand, 6=China, 7=Korea

criteria produces four distinct groups. Interestingly, the groups are identical to those produced by MTC criteria though the processes of merging are different as shown in Table 7 and Figure 3.

The first group consists of Malaysia, Thailand and Korea, all of which are characterized by average in three variables, namely exchange rate volatility, interest rates volatility and inflation differentials. The second group comprises of Indonesia and the Philippines, particularly characterized by low volatility in real interest rates and high inflation differentials. Singapore and China are both alone in their own groups. One feature that only belongs to Singapore is low inflation differential

Figure 4. Dendogram of Group Average Clustering (OCA 1998-2004)

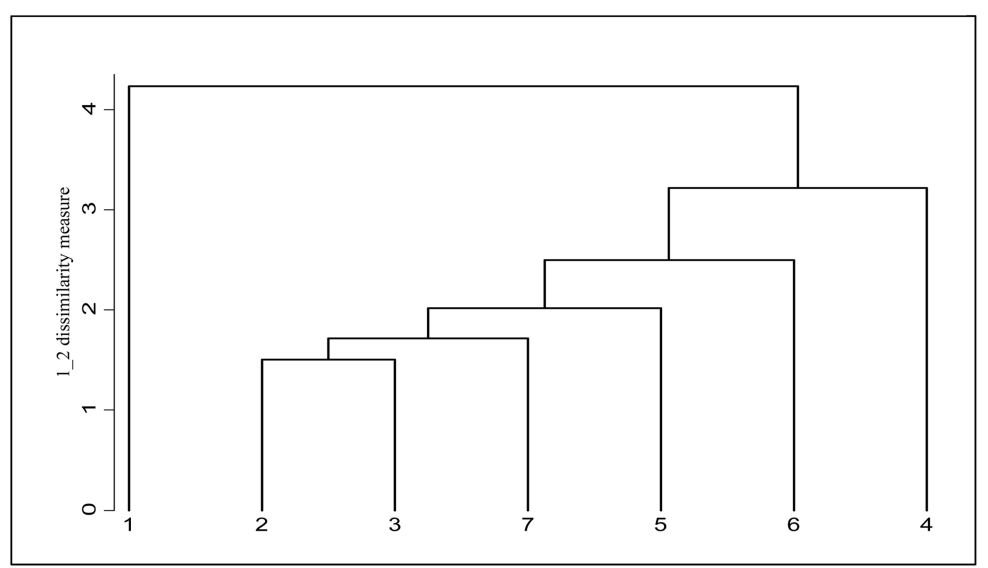

*Note: $1=$ Indonesia, 2=Malaysia, 3=Philippines, 4=Singapore, 5=Thailand, $6=$ China, $7=$ Korea 
Table 8. Group Average Clustering Agglomeration Schedule (1998-2004: OCA)

\begin{tabular}{clccc}
\hline \multirow{2}{*}{ Stage } & \multicolumn{2}{c}{ Cluster Combined } & Dissimilarity & $\begin{array}{c}\text { Number of } \\
\text { Clusters }\end{array}$ \\
\cline { 2 - 3 } & Cluster X & Cluster Y & Coefficients & 1.503 \\
2 & Malaysia & Philippines & 1.715 & 5 \\
2 & Cluster 1 & Korea & 2.020 & 4 \\
3 & Cluster 2 & Thailand & 2.497 & 3 \\
4 & Cluster 3 & China & 3.219 & 2 \\
5 & Cluster 4 & Singapore & 4.234 & 1 \\
6 & Indonesia & Cluster 5 & & 1 \\
\hline
\end{tabular}

while China is characterized by high exchange rate volatility and high interest rate volatility.

After the crisis, the grouping has several noticeable changes. Also, the grouping in this case is not very clear compared to the grouping in the previous three cases. The process of the grouping is summarized in Table 8 and illustrated in Figure 4.

The first group comprised of Malaysia, the Philippines, Thailand and Korea, with the first two countries sharing the highest similarity, while Thailand shows the least similarity with the others in the group. The merging process suggests that although the four countries are grouped together, the homogeneity among them is low, as indicated by the fact that group only shares one feature, namely average inflation differentials. The second group contains China. However, there is no single character that solely belongs to this country. Singapore occupies the third group, predominantly characterized by low percentage of trade with Japan. Lastly, similar to the grouping by MTC criteria in the post crisis period, the analysis puts Indonesia alone in the fourth group. The merging process suggests that Indonesia is quite different from other countries in term of OCA and it is characterized by high exchange rate volatility and high inflation differential.

\section{Discussion}

Table 9 and Table 10 summarize the classifications of ASEAN + 3 countries based on the MTC and OCA criteria respectively. Generally, the clusters produce clear cut segmentations yet differ between pre- and post-crsis period, demonstrating that the ASEAN+3 economies are not homogenous in terms of the MTC and OCA criteria..

Homogeneity of economies of the member countries is an important aspect to 
Table 9. Classification of ASEAN +3 by MTC Criteria

\begin{tabular}{cccccc}
\hline & Deficits & Debt & Volt. ER & Inf. Diff & Int Rates \\
\hline 1991-1997 & High & High & Ave & High & High \\
$\{$ Indonesia, Philippines & Mixed & Mixed & Ave & Mixed & Mixed \\
\{Malaysia, Thailand, Korea $\}$ & Low & Low & Ave & Low & Low \\
\{Singapore\} & High & Low & High & High & Ave \\
\{China\} & & & & & \\
1998-2004 & Mixed & Mixed & Ave & Ave & Ave \\
$\begin{array}{c}\text { \{Malaysia, Philippines, Thailand }\} \\
\text { \{Singapore, Korea, China } \\
\text { \{Indonesia\} }\end{array}$ & Mixed & Low & Mixed & Mixed & Mixed \\
& & High & High & High & High \\
\hline
\end{tabular}

*Notes: Table shows group classifications according to whether the countries in each group have low (Low), average (Ave) or high (High) values for each criterion. A group is regarded as mixed if it has a dispersion of values for a criterion.

Table 10. Classification of ASEAN +3 by OCA Criteria

\begin{tabular}{cccccc}
\hline & GDP & Exc Rate & Int Rates & Trade & Inflation \\
\hline 1991-1997 & Mixed & Ave & Ave & Mixed & Ave \\
\{Malaysia, Thailand, Korea $\}$ & Ave & Ave & Low & Mixed & High \\
\{Indonesia, Philippines & High & Ave & Ave & Low & Low \\
\{Singapore & High & High & High & Ave & High \\
\{China\} & & & & & \\
1998-2004 & & & & & \\
Malaysia, Philippines, Thailand, & Mixed & Ave & Mixed & Mixed & Ave \\
Korea & High & Ave & Low & High & Low \\
\{China & Low & Ave & Low & Low & Low \\
\{Singapore & Ave & High & High & High & High \\
\{Indonesia $\}$ & & & & & \\
\hline
\end{tabular}

*Notes: Table shows group classifications according to whether the countries in each group have low (Low), average (Ave) or high (High) values for each criterion. A group is regarded as mixed if it has a dispersion of values for a criterion.

ensure stability in a monetary union. Results from this study suggest that the immediate formation of a monetary union for ASEAN+3 would entail serious potential costs because the 'one size fits all' policy is not suitable for this group of countries. Kim and Chow (2003) asserted that each country in East Asia seems sufficiently unique, due to different resource dependencies, growth experience and/ or economic policies. Although the region enjoys high trade integration, so far, it has failed to produce a homogenous group similar to that of the Western Europe. According to Bayoumi, Eichengreen and Mauro (2000), ASEAN countries are at 
vastly different levels of economic development, with Singapore's per capita income more than 40 times that of Indonesia. Singapore also has one of the most advanced financial markets in the world and is one of the leading foreign-exchange trading centers. Although other ASEAN countries, such as Indonesia and the Philippines, have their own financial markets and are involved in foreign-exchange trading, their facilities and the levels of the trading are inferior and much lower than those in Singapore. Even after completely isolating Singapore, and focusing only on the other core ASEAN members, the countries still have vast differences. For example, Malaysia's per capita GDP is more than twice that of Indonesia. Economic integration would be easier if countries have similar level of economic development and share common financial systems (Bayoumi \& Mauro, 1999). Based on aggregate supply disturbances, Malaysia, Indonesia and Singapore are said to have relatively similar disturbances, while the Philippines and Thailand experience more idiosyncratic shocks (Bayoumi and Mauro, 1999).

Different classification of countries between pre- and post-crisis periods may be due to the differences in economic performances of each ASEAN+3 member countries before the crisis, and the different impact of the 1997 financial crisis on these countries. Foreign exchange reserves is an important indicator to observe how countries react to a financial crisis. Large foreign exchange reserves could help in financing a current account deficit, and enhance the credibility of a fixed exchange rate policy. This, together with a small external debt burden, reduces the risk of external crises, and enables a country to finance a current account deficit at lower costs. A good measure of reserve adequacy is the ratio of money assets to foreign reserves as all liquid money assets can potentially be converted into foreign exchange in the event of an exchange rate crisis. Calvo (1998) suggests that the ratio of $\mathrm{M} 2$ to foreign reserves represents a broad measure of liquid monetary

Table 11. The Ratio of M2 to Foreign Exchange Reserves - ASEAN +3

\begin{tabular}{cccccccc}
\hline & 1991 & 1992 & 1993 & 1994 & 1995 & 1996 & 1997 \\
\hline China & 8.00 & 21.39 & 26.93 & 10.29 & 9.65 & 8.55 & 7.76 \\
Indonesia & 5.51 & 5.61 & 6.09 & 6.55 & 7.09 & 6.50 & 7.37 \\
Korea & 8.33 & 7.20 & 6.91 & 6.45 & 6.11 & 6.51 & 10.50 \\
Malaysia & 2.99 & 2.64 & 2.09 & 2.47 & 3.33 & 3.66 & 4.99 \\
Philippines & 4.82 & 4.35 & 4.90 & 4.86 & 5.86 & 4.50 & 6.97 \\
Singapore & 1.18 & 1.17 & 1.05 & 1.06 & 1.05 & 1.03 & 1.17 \\
Thailand & 4.10 & 4.10 & 4.05 & 3.84 & 3.69 & 3.90 & 5.29 \\
\hline
\end{tabular}


assets to foreign reserves. A rise in this ratio indicates lower ability of a country to reduce the risk of external crises.

Table 11 shows an increasing trend of the ratio of M2 to foreign reserves for most of the ASEAN+3 countries prior to the financial crisis. However, the ratios varied among the countries. Singapore has the lowest ratio which means that it has low risk of external crises and the impact would be minimal compared to other countries if a crisis occurred. Korea and Indonesia have the highest ratio that makes them highly vulnerable to crises. In the case of China, despite the high ratio, the ability of Chinese residents to convert domestic liquid assets into foreign currency was severely limited by the widespread capital controls that were absent in most of the other countries in the region.

The economic recovery of the ASEAN+3 countries also varied. By the first quarter of 1999, there were signs of economic recovery in most of the crisisaffected countries. For example, industrial production and GDP in Korea, Thailand and Malaysia started to recover, and their GDP were expected to show positive growth in 1999. Signs of recovery could also be observed in other East Asian countries like Singapore and the Philippines. However, the Indonesian economy's recovery was still limited to financial sector and the recession had not yet bottomed out, which was due to serious policy and political uncertainties together with the delay in the banking sector and corporate restructuring process.

\section{Conclusion}

This study has investigated the homogeneity of ASEAN+3 that could be used as an indicator of their readiness in forming a monetary union. Two cluster analysis methods, fuzzy cluster analysis and group average cluster analysis, were used in grouping the countries. Two sets of data were used, one based on the MTC, and the other on the OCA theory. The data were organized into two time periods, 19911997 and 1998-2004, to examine the impact of the 1997 Asian financial crisis. Classifications using both methods, interestingly, produce almost identical results.

The classification based on the MTC criteria for the pre-crisis period grouped the countries into four clusters. The first group consists of Indonesia and the Philippines, the second group comprises of Malaysia, Thailand and Korea, and the third and fourth groups contain Singapore and China, respectively. For the postcrisis period classification yield three groups. The first group consists of Indonesia, the second group contains Malaysia, Philippines and Thailand, while the third 
group has Singapore, China and Korea.

Similar phenomenon is observed on the grouping using OCA data. Interestingly, the classification based on the OCA theory during the pre-crisis period is similar to that by using the MTC data during the same period. However, during the postcrisis period, the ASEAN +3 countries are classified into four groups. The first group contains Malaysia, the Philippines, Thailand and Korea, while the other three groups consist of only one country each, namely Singapore, China and Indonesia, respectively. Our results also reveal that the clusters produced by using any type of data have low similarity and suggest that the economies of ASEAN+3 measured by MTC and OCA criteria are not homogenous. The different classification/clusters before and after the 1997 financial crisis indicates the varied impact of the Asian financial crisis on ASEAN+3 economies and the different response of each economies to the crisis.

Overall, our findings suggest that it is not optimal for ASEAN+3 to form a monetary union at present. The 'one-size-fits-all' monetary policy would be inappropriate for certain ASEAN+3 members and the formation of a monetary union would entail serious potential cost.

Received 18 September 2007, Revised 12 March 2008, Accepted 21 March 2008 


\section{Appendix}

Table A1. Number of Cluster Determination (Using Fuzzy Clustering \& Maastricht Treaty Criteria)

\begin{tabular}{|c|c|c|c|c|c|c|c|c|}
\hline \multirow{3}{*}{ Period } & \multirow{3}{*}{$\begin{array}{c}\text { \# of } \\
\text { Clusters }\end{array}$} & \multicolumn{7}{|c|}{ MTC Criteria } \\
\hline & & \multirow{2}{*}{$\begin{array}{c}\text { Dunn's } \\
\text { Coefficient }\end{array}$} & \multicolumn{5}{|c|}{ Silhouette Width (for each cluster) } & \multirow{2}{*}{$\begin{array}{c}\text { Avg. } \\
\text { Silh. } \\
\text { Width }\end{array}$} \\
\hline & & & Cluster 1 & Cluster 2 & 2Cluster 3 & Cluster 4 & 4Cluster 5 & \\
\hline \multirow{3}{*}{ 1991-2004 } & 2 & 0.1522 & 0.4444 & 0.0395 & & & & 0.3287 \\
\hline & 3 & 0.4029 & 0.0000 & 0.0000 & 0.3195 & & & 0.2282 \\
\hline & 4 & 0.4698 & 0.1290 & 0.0000 & 0.1474 & 0.0981 & & 0.1070 \\
\hline \multirow{4}{*}{ 1991-1997 } & 2 & 0.2262 & 0.6949 & 0.0769 & & & & 0.2535 \\
\hline & 3 & 0.4413 & 0.0000 & 0.6784 & 0.2592 & & & 0.3419 \\
\hline & 4 & 0.5864 & 0.4303 & 0.0000 & 0.0000 & 0.6030 & & 0.3567 \\
\hline & 5 & 0.7053 & 0.0000 & 0.1966 & 0.0000 & 0.5698 & & 0.2190 \\
\hline \multirow{4}{*}{ 1998-2004 } & 2 & 0.2052 & 0.4895 & -0.0613 & & & & 0.2534 \\
\hline & 3 & 0.4620 & 0.0000 & 0.1804 & 0.6341 & & & 0.2842 \\
\hline & 4 & 0.5514 & 0.1711 & 0.5441 & 0.0000 & 0.0000 & & 0.2288 \\
\hline & 5 & 0.7010 & 0.0000 & 0.0000 & 0.0000 & 0.4753 & 0.1154 & 0.1688 \\
\hline
\end{tabular}

Table A2. Number of Cluster Determination (Using Fuzzy Clustering \& OCA Criteria)

\begin{tabular}{|c|c|c|c|c|c|c|c|c|}
\hline \multirow{3}{*}{ Period } & \multirow{3}{*}{$\begin{array}{c}\text { \# of } \\
\text { Clusters }\end{array}$} & \multicolumn{7}{|c|}{ OCA Criteria } \\
\hline & & \multirow{2}{*}{$\begin{array}{c}\text { Dunn's } \\
\text { Coefficient }\end{array}$} & \multicolumn{5}{|c|}{ Silhouette Width (for each cluster) } & \multirow{2}{*}{$\begin{array}{c}\text { Avg. } \\
\text { Silh. } \\
\text { Width }\end{array}$} \\
\hline & & & Cluster 1 & Cluster 2 & Cluster 3 & Cluster 4 & Cluster 5 & \\
\hline \multirow{4}{*}{ 1991-2004 } & 2 & 0.2337 & 0.5526 & 0.0172 & & & & 0.2467 \\
\hline & 3 & 0.4852 & 0.4497 & 0.3917 & 0.0000 & & & 0.3606 \\
\hline & 4 & 0.5272 & 0.0000 & 0.3388 & 0.1426 & 0.2907 & & 0.2206 \\
\hline & 5 & 0.7278 & 0.0000 & 0.0000 & 0.0000 & 0.0000 & 0.2038 & 0.0874 \\
\hline \multirow{4}{*}{ 1991-1997 } & 2 & 0.1490 & 0.4413 & -0.0183 & & & & 0.2444 \\
\hline & 3 & 0.3872 & 0.3921 & 0.0000 & 0.3767 & & & 0.3273 \\
\hline & 4 & 0.4990 & 0.0032 & 0.4014 & 0.0000 & 0.3429 & & 0.2136 \\
\hline & 5 & 0.6794 & 0.0000 & 0.2703 & 0.0000 & 0.0000 & -0.0609 & 0.0598 \\
\hline \multirow{4}{*}{ 1998-2004 } & 2 & 0.0002 & -0.0775 & 0.2207 & & & & 0.0929 \\
\hline & 3 & 0.3849 & 0.0000 & 0.0000 & 0.3351 & & & 0.2394 \\
\hline & 4 & 0.4784 & -0.2268 & 0.1615 & 0.2002 & 0.0000 & & 0.0385 \\
\hline & 5 & 0.6799 & 0.0000 & 0.0000 & 0.0000 & 0.0352 & 0.0000 & 0.0151 \\
\hline
\end{tabular}




\section{References}

Artis, M. and Zhang, W. (2001), "Core and Periphery in EMU: A Cluster Analysis", Economic Issue, 6, September, 39-60.

Bailliu, J. and Murray, J. (2003), "Exchange Rate Regimes in Emerging Markets", Bank of Canada Review, Winter 2002-2004.

Barro, R. J. ( 2001), "Economic Growth in East Asia Before and After the Financial Crisis", NBER Working Paper, 9072.

(Bayoumi, T. and Eichengreen, B. (1994), "One Money or Many? Analyzing the Prospects for Monetary Unification in Various Parts of the World", Princeton Studies in International Finance, No. 76, Department of Economics, Prince University, Princeton N.J.

Bayoumi, T. and Eichengreen, B. (1997b), "Optimum Currency Areas and Exchange Rate Volatility; Theory and Evidence Compared", International Trade and Finance: New Frontiers for Research, Cohen B (ed.), Essays in Honour of peter Kenen, Cambridge University Press: Cambridge.

Bayoumi, T., Eichengreen, B. and Mauro, P. (2000), "On Regional Monetary Arrangement for ASEAN", Journal of the Japanese and International Economies, $14,121-148$.

Bayoumi, T. and Mauro, P. (1999), "The Suitability of ASEAN for a Regional Currency Arrangement", IMF Working Paper, WP/99/162.

Boreiko, D. (2003), "EMU and Accession Countries: Fuzzy Cluster Analysis of Membership", International Journal of Finance and Economics, 8, 309-325.

Calvo, G.A. (1998), "Varieties of Capital Market Crises", in G. Calvo and M.King (eds.) The Debt Burden and its Consequences for Monetary Policy, Macmillan.

De Grauwe, P. (1994), “The Economics of Monetary Integration”, 2d rev. ed. New York: Oxford University Press.

Eichengreen, B. (1998), “Does Mercusor Need a Single Currency”, NBER Working Paper 6821, National Bureau of Economics Research Inc.

Fleming, J.M. (1971), “On Exchange Rtae Unification”, The Economic Journal, September, 467-488.

Frankel, J.A. (1999), "No Single Currency Regime Is Right for All Countries or at All Times", NBER Working Paper 7338, National Bureau of Economic Research.

Kaufmann, L. and Rousseuw (1990), "Finding Groups in Data - An Introduction to Cluster Analysis", Wiley Series in Probability Mathematical Statistics. Wiley: New York.

Kenen, P.B. (1969), "Theory of Optimum Currency Area, in Mundell R. and A. Swoboda", Monetary Problems in the International Economy, Chicago: University of Chicago Press.

Kim, Y. and Chow, H.K. (2003), "A Common Currency Peg in East Asia? Perspective from Western Europe", Journal of Macroeconomics, 25(3), 331-350. 
Lee, J.W., Park, Y.C. and Shin, K. (2002), “A Currency Union in East Asia”, mimeo (March).

Madhur, S. (2002), "Costs and Benefits of A Common Currency for ASEAN", ERD Working Paper No. 12.

McKinnon, R.I. (1963), “Optimum Currency Area”, American Economic Review, 53, 717-724.

McKinnon, R. and Schnabl, G. (2003), "The East Asian Dollar Standard, Fear of Floating, and Original Sin”, Unpublished Draft, Stanford University, http://www.stanford.edu/ $\sim$ mckinnon/papers.htm, September.

Mongelli, F.P. (2005), "What is European Economic and Monetary Union Telling Us about the Properties of Optimum Currency Area", Journal of Common Market Studies, 43(3), 607-635.

Mundell, R. (1961), "A Theory of Optimum Currency Areas", American Economic Review, 51, 509-517.

Mussa, M., Masson, P., Swoboda, A., Jadresic, E., Mauro, P. and Berg, A. (2000), "Exchange Rate Regimes in an Increasingly Integrated World Economy", IMF Occasional Paper 193.

Obstfeld, M. and Rogoff, K (1995), "The Mirage of Fixed Exchange Rates" Journal of Economic Perspectives, 9(4), 73-96.

Saxena, S.C. (2003), "India's Monetary Integration with the Rest of Asia: A Feasibility Study", University of Pittsburgh Working Paper.

Sterner, J. and Skoog, W. (2003), "ASEAN - an Optimum Currency Area?", Stockholm University Working Paper.

Trivisvanet, T. (2001), "Do East Asian Countries Constitute an Optimum Currency Area?", Duke University (Durham) Working Paper.

Tsang, S.K. (2002), "Optimum Currency Area for Mainland China and Hong Kong? Empirical Test", HKIMR Working Paper No.16/2002.

Williamson, J. (1999), "The Case for a Common Basket Peg for East Asian Currencies", in C. Stefan, J. Pisani-Ferry \& Y.C. Park (Eds), Exchange Rate Policies in Emerging Asian Countries (pp. 327-344), London: Routledge.

Wyplosz, C. (2001), "A Monetary Union in Asia? Some European Lesson", in G. David \& S. John (Eds.), Future Directions for Monetary Policies in East Asia (pp. 124-155), Sydney: Reserve Bank of Australias 